\title{
¿CÓMO TRADUCIR EL MARCADOR DISCURSIVO HOMBRE AL POLACO?
}

\begin{abstract}
Resumen. El presente estudio tiene por objetivo analizar cómo se traduce el marcador discursivo hombre al polaco. En la parte teórica se define brevemente esta clase de unidades lingüísticas, se describen los valores pragmáticos de dicha partícula y se diferencia el uso del marcador discursivo hombre de los usos de hombre como vocativo e interjección. En la parte práctica se cotejan secuencias comunicativas, que provienen de seis novelas españolas escritas por autores contemporáneos, con sus traducciones a fin de averiguar si transmiten los mismos valores pragmáticos.
\end{abstract}

Palabras clave: marcadores discursivos, funciones pragmáticas, hombre, traductología.

\section{Introducción}

Los marcadores discursivos, definidos por Portolés (1998: 25-26) como «unidades lingüísticas invariables, no ejercen una función sintáctica en el marco de la predicación oracional y poseen un cometido coincidente en el discurso: el de guiar, de acuerdo con sus distintas propiedades morfosintácticas, semánticas y pragmáticas, las inferencias que se realizan en la comunicación». Constituyen estos uno de los desafíos traductológicos más grandes, dadas sus múltiples funciones pragmáticas y varios matices emotivos que son capaces de transmitir, aunque tal vez no siempre sean reconocidos como problemáticos por los traductores más atentos al transvase de los juegos de palabras o las metáforas.

El presente artículo se centrará en el marcador hombre que, a diferencia de otros marcadores discursivos, como por ejemplo bueno o pues, goza de una naturaleza aún más compleja, ya que se usa también como un vocativo gramaticalizado para dirigirse a personas de ambos sexos. Gaviño

\footnotetext{
* Uniwersytet Łódzki.
} 
Rodríguez (2011: 4), basándose en investigadores como Portolés (2001 [1998]: 72-73), subraya que la distinción entre estas dos categorías reside en la variabilidad de hombre apelativo, ya que es sustituible por mujer, y la invariabilidad de hombre discursivo. No obstante, según ciertos hispanistas, como Gozalo Gómez y Martín Rodríguez (2008), una de las funciones primordiales de los vocativos, a saber, el llamar la atención del interlocutor, cabe dentro de la marca de los marcadores discursivos, en concreto los de control de contacto, los denominados enfocadores de la alteridad. Además, tanto los enfocadores como los vocativos pueden hacer hincapié en las relaciones que se establecen entre los dialogantes (Baran, 2010: 84), por lo cual contribuyen a la cortesía verbal. Todo esto puede llevar a la confusión entre hombre discursivo y hombre vocativo. Encima, la voz hombre se emplea como una interjección que manifiesta sorpresa o asombro o bien tiene valor conciliador, según la definición del diccionario de la RAE.

Ahora bien, en este estudio se analizarán tan solo los valores pragmáticos y las traducciones de dicho vocablo en función de marcador discursivo.

\section{2. Valores pragmáticos de hombre}

Antes de describir los valores comunicativos de hombre, conviene aclarar que, debido a un proceso de gramaticalización, dicho marcador se emplea tan solo en singular, no se combina con ningunos adyacentes (si bien se puede usar junto con un vocativo) y se refiere a personas de los dos sexos (Martín Zorraquino y Portolés, 1999: 4172-4173).

Respecto a las funciones, la principal, tal y como afirman Martín Zorraquino y Portolés (1999: 4082), es la de enfocador de la alteridad, o siguiendo la denominación del mismo Portolés (1998, apud Gozalo Gómez y Martín Rodríguez, 2008), la de marcador de control de contacto, a saber, un vocablo que contribuye al establecimiento y mantenimiento de las buenas relaciones entre interlocutores. Los dos investigadores (1999: 4173-4175) señalan que hombre protege la imagen positiva del enunciador por medio de las estrategias de cooperación, conllevando un matiz de familiaridad y de complicidad.

Una de las situaciones en las que dicha imagen está amenazada es cuando los hablantes no comparten las mismas opiniones o cuando uno de ellos no se pone de acuerdo con el otro. Entonces, hombre sirve para mitigar el desacuerdo (ejemplos 1 y 2), sea tajante o no, y permite prevenir un eventual enfado. Por otra parte, funcionando como partícula "reactiva" 
se muestra útil a la hora de reaccionar con alegría y agrado aun cuando las circunstancias o las aseveraciones del interlocutor desconciertan (ejemplo 3). Todos los ejemplos fueron recopilados por Martín Zorraquino y Portolés (1999: 4172-4175):

(1) $\quad-[\ldots]$ usted quiere que yo le diga a Añoveros que se vaya dos o tres días a Roma [...] - Hombre, no. No tan rápido.

(2) [...] PICAVEA: ¡Deslumbrador! [...]

GONZALO: (riendo) ¡Hombre, por Dios, no es para tanto!

(3) AVELINO: $[\ldots]$ ¿Cómo se llama usté? [...]

BENITA: Baranda.

AVELINO: (sonriendo) ¡Baranda! ¡Hombre ${ }^{1}$, qué casualidad! Usté Baranda, y yo, Escalera. ¡Nos completamos!

Asimismo las peticiones o los mandatos son capaces de afectar la imagen positiva del hablante, de ahí que se coloque dicho marcador después de un imperativo evitando así que este resulte molesto (Martín Zorraquino y Portolés, 1999: 4173-4174):

(4) No le des más vueltas al asunto, Paco, hombre.

Cabe añadir que al atenuar el valor exhortativo hombre puede adquirir cierto matiz paternalista (5), rebelde con un tono humorístico (6), o incluso arrogante en función de las relaciones establecidas entre los interlocutores, principalmente cuando existe una jerarquía vertical, tal y como en los ejemplos recopilados por Martín Zorraquino y Portolés (1999: 4176):

(5) Cámbiese usted de gafas y venga a la oficina con otro traje, hombre.

(6) MENÉNDEZ: ¿Pero usted la ha ofendido?

NUMERIANO: ¡Yo qué la voy a ofender, hombre!

Ahora bien, en su estudio sobre cómo tratar el marcador discursivo hombre en la clase de ELE, Gozalo Gómez y Martín Rodríguez (2008) llegan a diferenciar doce valores interactivos ${ }^{2}$ dependientes tanto de la entonación (y un eventual alargamiento vocal) como del contexto. Merece la pena destacar que, en el fondo, los matices comunicativos se deben más bien a los vocablos con los que hombre se combina, lo que se muestra en el recuadro infra:

${ }^{1}$ Como se puede observar en este ejemplo el empleo de dicho marcador no se restringe al tuteo sino que también se suele usar en contextos más formales.

2 Es preciso subrayar que esta clasificación minuciosa fue llevada a cabo por motivos puramente didácticos. 


\begin{tabular}{|l|l|}
\hline \multicolumn{1}{|c|}{ Valor comunicativo } & \multicolumn{1}{c|}{ Exponente } \\
\hline 1. Afirmación, acuerdo, permiso & $\begin{array}{l}\text { Claro, hombre; pues, claro, hombre; } \\
\text { sí, hombre, (sí); hombre por supuesto; etc. }\end{array}$ \\
\hline $\begin{array}{l}\text { 2. Negación, contradicción, reserva, } \\
\text { rechazo }\end{array}$ & $\begin{array}{l}\text { (No) hombre, (no); que no, hombre (que } \\
\text { no); hombre, por Dios }\end{array}$ \\
\hline $\begin{array}{l}\text { 3. Estímulo, insistencia, efecto } \\
\text { tranquilizador }\end{array}$ & $\begin{array}{l}\text { Venga, hombre; vamos, hombre; } \\
\text { anda, hombre }\end{array}$ \\
\hline 4. Explicación, demostración de razones & Pues, hombre \\
\hline 5. Búsqueda de palabras adecuadas & Hombre, pues \\
\hline $\begin{array}{l}\text { 6. Sorpresa, decepción, sentimiento, } \\
\text { fastidio }\end{array}$ & Vaya, hombre \\
\hline 7. Incredulidad & Venga, hombre; anda hombre \\
\hline 8. Desacuerdo & Vamos, hombre \\
\hline 9. Respuesta a una disculpa & Nada, hombre \\
\hline 10. Desprecio & Toma, hombre \\
\hline 11. Desacuerdo parcial, reserva & $\begin{array}{l}\text { Pero, hombre; hombre, pero; hombre, } \\
\text { es que }\end{array}$ \\
\hline 12. Regaño, llama de atención & Pero, hombre; pero hombre por Dios \\
\hline
\end{tabular}

En cambio, Santos (2003: 410, apud Gaviño Rodríguez, 2011: 3-5) se 224 limita a enumerar seis valores de la partícula en cuestión: 1) partícula fática que expresa indecisión ante lo dicho, 2) partícula autorreactiva de reformulación, 3) partícula reactiva que indica disgusto (en ocasiones seguida por un reproche), 4) partícula reactiva que manifiesta aprobación, 5) expresión de sorpresa, 6) vocativo de carácter fático.

Por último, Gaviño Rodríguez (2011: 5-7) propone otra forma de describir las funciones de hombre, rechazando clasificaciones tan escrupulosas como la de Gozalo Gómez y Martín Rodríguez (2008) o la de Santos (2003) mencionadas supra. Para el investigador, este tipo de análisis es paradójicamente bastante incompleto $y$, además, subordinado a los factores circunstanciales. De hecho, resulta imposible catalogar todos los matices que dicho marcador es capaz de indicar en combinación con otras expresiones. Ahora bien, según su punto de vista, convendría atribuir los valores pragmáticos de una forma "global", diferenciando dos papeles principales, a saber, marcador introductor de reformulación (7) y marcador de reacción conversacional (8).

(7) Yo lo haría todo; hombre, no todo, pero casi todo.

(8) A: Vas a venir entonces.

B: ¡Hombre, faltaría más! 
Desempeñando el primer papel hombre señala que el enunciador pretende reformular lo dicho, mientras que actuando como partícula reactiva, introduce las palabras que expresan la actitud y las emociones del hablante en respuesta a una información nueva o ya conocida. No obstante, no es el marcador discursivo hombre sino precisamente estos enunciados que le acompañan los que proporcionan los datos necesarios para la interpretación de la postura y los sentimientos del enunciador (Gaviño Rodríguez, 2011: 7-8).

En cuanto a la colocación del marcador en cuestión, según observan Llamas Saiz y Martínez Pasamar (2007: 753; con citas de manuales de ELE), este puede utilizarse tanto en intervenciones iniciativas (9) como en reactivas (10), pero su repetición es más natural en oraciones reactivas (11):

(9) - ¡Hombre, Jorge! Mira, te voy a presentar a un chico majísimo... Luis... Jorge.

- ¡Hola!, ¿qué tal?

- ¿Qué hay?, ¿cómo estás?

(10) - ¿Sois profesores?

- Sí. Carla enseña matemáticas y yo, literatura.

- Pero sois muy jóvenes, ¿no?

- Hombre, yo tengo 30 años y Carla, 29.

(11) - Estás guapísima.

- Hombre, hombre..., sin exagerar...

Curiosamente, en ciertas ocasiones, hombre (12) ni siquiera requiere que esté presente un interlocutor, pues se pueden pronunciar enunciados tales como el ejemplo infra en perfecta soledad (Gaviño Rodríguez, 2011: 8):

(12) Hombre, ¿dónde habré puesto yo las gafas?

Teniendo en cuenta todas las clasificaciones expuestas anteriormente, organizaré las secuencias comunicativas seleccionadas en cinco secciones en las que el marcador en cuestión refuerza la conformidad, mitiga el desacuerdo, atenúa el valor exhortativo, reacciona positivamente a lo dicho e introduce reformulación.

\section{Análisis del corpus}

En este apartado analizaré fragmentos recopilados de seis novelas españolas contemporáneas que se han traducido al polaco y cuyos diálogos se caracterizan por un lenguaje coloquial, así como por un 
número significativo de usos de los marcadores discursivos, entre otros de hombre. Las novelas en cuestión son las siguientes:

- Caperucita en Manhattan de Carmen Martín Gaite (=CM)

- El corazón del Tártaro de Rosa Montero (=CT)

- Los besos en el pan de Almudena Grandes (= BP)

- Riña de gatos de Eduardo Mendoza (= RG)

- La verdad sobre el caso Savolta de Eduardo Mendoza (=CS)

- Tres vidas de santos de Eduardo Mendoza (= TV)

Empezaré por las seis intervenciones reactivas en las que hombre refuerza la conformidad entre los hablantes:

$-[\ldots]$ ¿Ha entendido la naturaleza y el alcance de su misión?

- Sí, hombre. No tiene complicación (RG 89).

- [...] Zrozumiał pan charakter i zasięg swojej misji?

- Tak, człowieku. Nie jest skomplikowana (108).

- ¿Me dirá dónde puedo encontrarla?

- Sí, hombre, sí, no sufras (CS 152).

- Powie mi pani, gdzie mógłbym ją znaleźć?

- Powiem Ø, co mam nie powiedzieć (191).

(15) - Pues eso, que te vas andando [...].

- Sí, hombre, pues que conste en acta [...] (BP 111).

- No to będziesz musiała się przespacerować [...].

- \ak sobie chcesz. Ale wszyscy na pewno to dobrze zapamiętają (142-143).

(16) - ¿Me acercáis al pueblo en coche?

- Pues, claro, hombre, pero antes... (BP 174)

- Podwieziecie mnie do domu samochodem?

- No jasne Ø, ale najpierw [...] (228)

El primer fragmento, a nuestro parecer, indica más irritación o hasta reproche en la versión meta, mientras que se obtendrían efectos más próximos a los del original reduplicando tak o anteponiendo la partícula no que, tal y como lo describe el diccionario de Doroszewski, refuerza expresivamente el asentimiento. En la secuencia (14) la omisión priva la versión polaca del tono amistoso que, dada la asimetría del trato causada por la edad y la posición social entre los interlocutores, sería posible expresar mediante un vocativo chtopcze. Asimismo las traducciones de las intervenciones reactivas (15 y 16) omiten el marcador, lo cual parece una decisión acertada, pues no jasne constituye un acuerdo bastante fuerte $\mathrm{y}$, al contrario jak sobie chcesz sirve para aceptar una sugerencia pero a regañadientes, lo cual cuadra con el contexto. 
En la mayoría de los fragmentos recopilados (once de treinta), hombre suaviza la disconformidad y la discrepancia de opiniones creadas entre los interlocutores.

(17) No, hombre, eso está por la parte de arriba del jamón (CM 14).

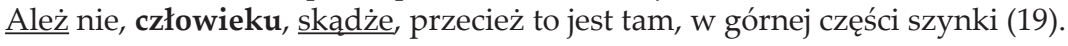

(18) [en respuesta a unos elogios de su marido]

- No exageres, hombre -dijo la señora Allen (CM 46).

- Nie przesadzaj, kochany - powiedziała pani Allen (66).

(19) ¿Y a usted le llaman el Rey de las Tartas? ¡Vamos, hombre! La Reina está aquí, aquí tiene usted a la verdadera Reina de las Tartas (CM 46).

I pana nazywają Królem Tortów? Gruba przesada, proszę pana! Królowa jest tutaj, tutaj ma pan przed sobą prawdziwą Królową Tortów (67).

(20) Mateo, ponme otro tinto y lo mismo aquí al caballero. Que sí, hombre, que luego paga usted otra ronda y tan contentos (RG 46).

Mateo, jeszcze jeden kieliszek czerwonego i to samo dla pana. Ależ tak, $\varnothing$, potem pan mi postawisz kolejkę i będzie dobrze (56).

(21) [en respuesta al enunciado en el que el interlocutor dice que el pintor tan solo pintó retratos de la familia real]

- Hombre, no está mal -dijo Paquita [...] (RG 160)

- Ø Całkiem niezły obraz - skomentowała Paquita [...] (191)

(22) $-[\ldots]$ La vida que lleva no es para ser descrita. Y el futuro que le espera, ni que decir tiene.

- Hombre, si estalla la revolución, quizá se arregla el caso (RG 170).

- [...] Jej życie jest nie do opisania. A co ją czeka, nie trzeba mówić.

- Ø Jeśli wybuchnie rewolucja, może jej los się polepszy (204).

(23) - ¿Para matarme? -dijo Anthony con incredulidad.- ¡Venga, hombre, déjese de tonterías! (RG 315)

- Żeby mnie zabić? - powtórzył Anthony z niedowierzaniem. - Ależ, człowieku, daj spokój tym głupstwom (379).

(24) - ¿Pero no cree usted que se han puesto de culo?

- Hombre, de culo, lo que se dice de culo..., no sé. Tal vez dan esa impresión (CS 161-162).

- A nie uważa pan, że poszli w krzaki?

- Bo ja wiem... W krzaki... to, co dosłownie myślimy mówiąc „,w krzaki” .. Bo ja wiem... Chociaż można odnieść takie wrażenie... (202)

(25) «[...] ¿Qué pasa con los marginados, a ver?»

«Nada, hombre, no seas picajoso. [...]» (TV 108)

- [...] Czego wy właściwie chcecie od marginesu społecznego, co?

- Niczego, Ø, nie bądź taki drażliwy (160). 
(26) Pero, hombre, ¿cómo me dices eso? ¿Qué trabajo puedo ofrecerle yo a tu hijo? (BP 69) Nie wiem, jak mam to rozumieć, nie wiem, jaką pracę mógłbym zaoferować twojemu synowi (88).

(27) $\quad-[\ldots]$ El gobierno de la comunidad nos quiere cerrar en el centro.

- Pero, ¿qué dices, hombre? -Venancio niega con la cabeza [...] (BP 135)

- [...] Władze Madrytu chcą nam zamknąć ośrodek zdrowia.

- Ale jak to Ø? - Venancio kręci głową [...] (176)

Dicho marcador, en las intervenciones reactivas (17) y (23), se traduce al polaco con el vocativo polaco człowieku que, según la definición del diccionario de Doroszewski, expresa familiaridad y corresponde a los vocativos mój drogi (literalmente: mi querido), bracie (hermano), przyjacielu (amigo), bój się Boga (literalmente: teme a Dios, pero usado para expresar asombro o desaprobación). En el fondo, la traducción literal polaca goza más bien de una índole neutral, lo corroboran las expresiones sinonímicas, de ahí que su tono emotivo dependa de la entonación y de factores contextuales. En el ejemplo (18), el traductor opta por el vocativo kochany (equivalente de cariño) que, por su ternura, contribuye a borrar el efecto de la disconformidad de opiniones y que al mismo tiempo se adecua al contexto. La secuencia (19) comprende un desacuerdo bastante fuerte, quizá 228 teñido de desprecio, donde el valor atenuante de hombre se vierte al polaco mediante la fórmula de cortesía prosze pana, la cual puede tener efectos tranquilizantes con tal de que se pronuncie con una entonación apropiada. El fragmento (20) contiene una réplica al desacuerdo implícito en la cual el enunciador insiste, tal vez con un tono ligeramente paternalista, en pagar una ronda a pesar de la protesta de su interlocutor. La traducción omite el marcador, pero utiliza acertadamente una mezcla de tratamiento de usted (pan) y del tuteo (uso del verbo en la segunda persona del singular), aunque conviene advertir que este procedimiento se considera descortés hasta grosero, excepto cuando aparece entre personas que se conocen relativamente bien y aun así no se tratan de tú. Las versiones polacas de las secuencias comunicativas (21 y 22) omiten el marcador, aunque se podría haber precedido el enunciado por la expresión nie no para indicar una ligera oposición en la primera y por la partícula no para señalar que la réplica se relaciona de alguna forma con lo dicho anteriormente. Respecto a la ligera oposición introducida por hombre como preludio concesivo en (24), la traductora la ha trasformado en una reacción más vacilante, en tanto que, se habría obtenido efectos más próximos a los originales si se la hubiera sustituido por la muletilla wie pan. En las versiones meta de las secuencias (25-27) se omite el marcador y en las dos últimas se cambia, además, la postura del enunciador así como las emociones que expresa. La traducción 
del diálogo (26) transmite más bien consternación y confusión, mientras que la del (27) sorpresa e incredulidad. Ahora bien, para poder trasvasar la disconformidad sería necesario volver a traducir todos los enunciados en los que aparece el marcador. En cuanto a la réplica del (25), la omisión del marcador parece adecuada; no obstante, la reduplicación de niczego podría atenuar aún más la aparente disconformidad.

En las secuencias comunicativas a continuación el marcador discursivo se emplea a fin de animar al interlocutor a actuar, sin que la petición resulte fastidiosa o categórica. En los ejemplos (28, 29, 32, 33 y 34) hombre sigue al imperativo, mientras que en el (30) está intercalado entre dos imperativos. La secuencia (31) constituye un caso distinto, puesto que hombre está colocado después de otro marcador discursivo, esto es, venga que sirve justamente para animar al interlocutor.

(28) - $\quad[\ldots]$ Ayúdame a aderezar la mesa. Mira, no hay manchas de sangre ni nada por el estilo. Empuja, hombre, que yo solo no puedo (CS 253).

- [...] Pomóż mi podnieść stół. Popatrz, nigdzie ani śladu krwi. № rusz się, człowieku, bo sam nie poradzę (310).

(29) - No podría. Estoy tan borracho que no podría.

- ¡Quite, hombre, quite! Mi mujer es de las que resucitan a los muertos (CS 264).

- Teraz nic by nie wyszło. Jestem tak pijany, że nic by nie wyszło.

- Odwagi, człowieku, moja żona należy do tych, co wskrzeszają umarłych (323).

(30) - ¿Nos estarán espiando? [...]

- No creo, ¡Y guarda ese cacharro, hombre! (RG 254)

- Czyżby ktoś nas śledził? [...]

- Nie sądzę, a ty schowaj lepiej tego gnata Ø! (305)

(31) No puedes irte a la cama, Miguel. Es por la mañana y te acabas de levantar. Venga, hombre, no seas tonto... quítate las manos de la cara y mírame... (CT 18)

Nie możesz iść spać. Jest ranek, dopiero wstałeś. No, już, chłopie, nie bądź niemądry... Zabierz ręce od buzi i popatrz na mnie... (22)

(32) Déjame, hombre, pero qué te molesta... (CT 80)

Wpuść mnie, stary, co ci szkodzi... (102)

(33) [...] y Mari siempre diciendo lo mismo, ¡ay, sí!, ¡ay, qué bien!, ¡ay, muchas gracias!, ¡ay!, pero hazle caso a Juan Francisco, hombre [...] (BP 68)

$[\ldots]$ a Mari przytakuje, $[\ldots]$

- Ach tak? No, to świetny pomysł, dzięki za radę, powinieneś Juan Francisco, zobacz Ø, jak dobrze mu się wiedzie! (87)

(34) Échale una mano, hombre (BP 116).

Pomóż mu Ø (151).

(35) Tranquilo... Tranquilo, hombre, que no pasa nada... (CT 19)

Spokojnie... Uspokój się, chłopie, nic się nie dzieje... (24) 
En la intervención reactiva (28), el hablante pide ayuda a su interlocutor atenuando la petición con hombre. En la traducción se usa el equivalente człowieku en función de vocativo y la partícula no que refuerza el imperativo, por ende la versión polaca desempeña el papel de incentivar a la acción pero carece del matiz mitigante. Los claros fines tranquilizadores del marcador en cuestión que se muestran en la secuencia (29) se trasvasan al polaco otra vez mediante el vocativo człowieku. Como en esta situación el enunciador está animando al interlocutor a presentarse a la mujer de aquel y en la versión meta se emplea la expresión odwagi (coraje), no hace falta suavizar el incentivo sino más bien reforzarlo precisamente por medio de dicho apelativo. En cambio, en el fragmento (30), hombre queda omitido en la traducción, lo cual, a nuestro modo de ver, disminuye la fuerza emotiva del mandato, mientras que a estos efectos se hubiera podido añadir la partícula no después del imperativo schowaj. La traductora de las secuencias (31 y 32) en ambos casos ha optado por vocativos coloquiales que contribuyen a la complicidad, pero no empujan a la acción. Las últimas dos intervenciones reactivas (33 y 34) omiten el enfocador en la versión polaca, mientras que se podría haber empleado la partícula no, cuya función incentiva se ha mencionado supra. En el diálogo (35) hombre se junta con palabras tranquilizantes y no con un imperativo propiamente dicho, pero, en realidad, estas invitan al interlocutor a tranquilizarse, por lo tanto también en esta ocasión la función del marcador es semejante a la de las intervenciones (28-34). En la traducción aparece otra vez el vocativo coloquial chtopie que, sin embargo, no desempeña el mismo papel, como ya se ha indicado anteriormente.

En función de partícula "reactiva", hombre introduce las expresiones de varias emociones, como se puede apreciar en los ejemplos a continuación:

(36) ¡Vaya, hombre! ¿Y por qué no llaman aquí? (CM 18)

Coś takiego Ø! A dlaczego tutaj nie zadzwonią? (24)

(37) ¿Pero, Venancio, hombre, ¿no te has enterado?

Jak to, Venancio, Ø naprawdę o niczym nie wiesz? (176)

(38) - Anthony.

- ¿Antoñito? Hombre, eso ya está mejor (RG 35).

- Anthony.

- Antoñito? Ø Tak lepiej! (43)

(39) «[...] si le viene bien, pues me hace usted una lista, cuando pueda, y así no la tendré que andar molestando cada vez.»

«Hombre, así, a bote pronto, no sabría. Pero si vamos juntos a la biblioteca y vemos lo que hay, podemos hacer una lista sobre la marcha» (TV 104). 
- Jeśli można, może by mi pani zrobiła listę przy jakiejś okazji, to nie będę musiał bez przerwy pani męczyć.

- Ø Tak z głowy nie potrafię. Ale jeśli pójdziemy do biblioteki i zobaczymy, co tam mają będziemy mogli zrobić listę na miejscu (154).

(40) [la recepcionista en respuesta a la pregunta si había habido visitas o llamadas] - ¿Alguna? ¡Hombre, si desde que se inscribió usted en el hotel, esto parece el baile de la Bombilla! (RG 261)

- Ktoś? Człowieku, od czasu, gdy pan zamieszkał w tym hotelu, drzwi się nie zamykają (314).

(41) - ¿A mí? ¿Quién? ¿Dónde?

- ¿Dónde va a ser? ¿En la plaza de toros? En la Embajada, hombre, en la Embajada (RG 196).

- Na mnie? Kto? Gdzie?

- A czego się pan spodziewa? Że na arenie do korridy? W ambasadzie, człowieku, w naszej ambasadzie (235).

El marcador en los cuatro primeros fragmentos acompaña a las expresiones de sorpresa dotadas de un matiz de alegría (38) así como de desconcierto (39) y se ha omitido en las respectivas traducciones, si bien se transmite la consternación por medio de la expresión coś takiego en la versión polaca de la secuencia (36) y a través de naprawdę en la (37). Las dos últimas intervenciones reactivas manifiestan irritación y en ambas el marcador se traduce con el vocativo człowieku que, con una entonación adecuada, puede connotar enojo.

Finalmente, dos secuencias comunicativas comprenden el marcador en función de introductor de reformulación:

(42) La primera vez tiene diecisiete años y su novia -sí, hombre, aquella chica bajita y rubia, que era bastante sosa [...] (BP 45)

Po raz pierwszy odczuwa go, mając siedemnaście lat, kiedy jego narzeczonej - $\varnothing$ tej niziutkiej dziewczynie o jasnych włosach, która właściwie była nijaka [...] (61)

(43) - ¿Ya puede usted invitar a su amigo, ¿no? [...]. Sí, hombre, ese señor que antes desayunaba siempre con usted [...] (BP 124)

- Będzie pan mógł zaprosić na coś kolegę, prawda? [...]. No Ø, tego pana, co wcześniej przychodził tu na śniadanie [...] (161).

En el fragmento (42) el enunciador usa hombre con el objetivo de añadir más informaciones sobre la novia en cuestión y en el (43) el hablante pretende rectificar que el señor en cuestión quizá no sea un amigo del interlocutor. Las traducciones omiten el marcador aunque en el primer caso se podría haber optado por la muletilla no wiesz que se emplea en la lengua hablada con el fin de introducir explicaciones y en el otro znaczy que es una manera coloquial de iniciar una reformulación. 


\section{Conclusiones}

A pesar de que los diferentes valores del marcador discursivo hombre suponen dificultades en el proceso de traducción, el marcador hombre tiene, en general, partículas, expresiones o muletillas homólogas en polaco, lo que se refleja en el análisis de los fragmentos seleccionados.

Como se ha podido observar a lo largo del análisis, hombre, por su ambigua índole, provoca frecuentes usos inadecuados del vocativo polaco człowieku u otros vocativos del registro coloquial. Estos, si bien no son meros instrumentos para dirigirse al interlocutor y sirven, además, para indicar familiaridad, no se ajustan a todos los contextos. De ahí que los traductores hayan de buscar otras partículas o expresiones polacas, tales como no, wie pan, no wiesz, que contribuyan a mantener la imagen positiva del enunciador. Incluso en ciertas ocasiones la complicidad que implica dicho marcador se puede trasvasar al polaco por medios gramaticales, es decir, el empleo del verbo en la segunda persona del singular junto con la voz pan (usted).

Sin embargo, siempre que sea imposible transmitir los mismos valores pragmáticos, más vale omitir el marcador que añadir al texto matices inexistentes en el original. Ahora bien, en el corpus analizado el marcador se ha omitido diecisiete veces en un total de treinta intervenciones reactivas pese a que, en algunos casos, es posible encontrar equivalentes funcionales en polaco, como hemos intentado mostrar anteriormente.

Obviamente, sería imposible facilitar una lista completa de buenas soluciones prefabricadas para cada función de hombre, visto que este depende de los factores contextuales. Por lo tanto, a los traductores no les queda más remedio que descodificar correctamente los valores de dicho marcador a fin de no abusar del vocativo człowieku.

\section{Bibliografía}

BARAN, M. (2010). Emotividad y convención sociopragmática: una contribución al estudio del ethos comunicativo de la comunidad hispanohablante peninsular. Łódź: Wydawnictwo Uniwersytetu Łódzkiego.

BARAN, M. (2012). «Sociopragmática vs. traductología: enfocadores de la alteridad como problemas de traducción», Romanica Cracoviensia, 12, 117-132.

DOROSZEWSKI, W. (1996). Stownik jezzyka polskiego PWN [en línea] <https://sjp. pwn.pl/doroszewski $>$, fecha de consulta: 9 de septiembre de 2018. 
GAVIÑO RODRÍGUEZ, V. (2011). «Operaciones metalingüísticas del marcador discursivo hombre», MarcoELE. Revista de didáctica de ELE, 12 [en línea] $<$ https://marcoele.com/marcador-discursivo-hombre>, fecha de consulta: 9 de septiembre de 2018.

GOZALO GÓMEZ, P. y MARTÍN RODRÍGUEZ, M. (2008). «El marcador discursivo hombre y su tratamiento en el aula de E / LE», redELE, 14 [en línea] $<$ https://sede.educacion.gob.es/publiventa/d/20258/19/0>, fecha de consulta: 9 de septiembre de 2018.

GRANDES, A. (2005). Los besos en el pan. Barcelona: Tusquets.

GRA NDES, A. (2017). Pocałunki składane na chlebie. Katowice: Wyd. Sonia Draga (trad. K. OKRASKO).

LLAMAS SAÍZ, C. y MARTÍNEZ PASAMAR, C. (2007). «Hombre, enseñar español no es tan fácil la enseñanza del enfocador de alteridad hombre», en E. BALMASEDA MAESTU (coord.), Las destrezas orales en la enseñanza del español L2-LE: XVII Congreso Internacional de la Asociación del Español como lengua extranjera (ASELE): Logroño 27-30 de septiembre de 2006, vol. 2. Logroño: Universidad de la Rioja, 749-764.

MARTÍN GAITE, C. (1999). Kapturek na Manhattanie. Warszawa: Muza S.A. (trad. C. MARRODÁN CASAS).

MARTÍN GAITE, C. (2010). Caperucita en Manhattan. Madrid: Siruela.

MARTÍN ZORRAQUINO, M. A. y PORTOLÉS, J. (1999). «Los marcadores del discurso», en I. BOSQUE y V. DEMONTE (dirs.), Gramática descriptiva de la lengua española. Madrid: Espasa Calpe, 4051-4214.

MENDOZA, E. (1980). Prawda o sprawie Savolty. Warszawa: Państwowy Instytut Wydawniczy (trad. Z. CHĄDZYŃSKA).

MENDOZA, E. (2010a). La verdad sobre el caso Savolta. Pamplona: Leer-e.

MENDOZA, E. (2010b). Riña de gatos. Barcelona: Planeta.

MENDOZA, E. (2011). Trzy żywoty świętych. Kraków: Znak (trad. M. CHROBAK).

MENDOZA, E. (2012a). Tres vidas de santos. Barcelona: Seix Barral.

MENDOZA, E. (2012b). Walka kotów. Kraków: Znak (trad. M. CHROBAK).

MONTERO, R. (2003). Stąd do Tartaru. Warszawa: Muza S.A. (trad. A. MAZUŚ).

MONTERO, R. (2015). El corazón del Tártaro. Barcelona: Alfaguarra.

PORTOLÉS, J. (1998). Marcadores del discurso. Barcelona: Ariel. 